\title{
Clustered DNA damage induced by protons radiation in plasmid DNA
}

\author{
SUI Li ${ }^{1,2}$, WANG $\mathrm{Yu}^{1}$, WANG Xiao ${ }^{2}$, KONG FuQuan $^{2}$, LIU JianCheng ${ }^{2} \&$ ZHOU PingKun ${ }^{1 *}$ \\ ${ }^{1}$ Beijing Institute of Radiation Medicine, Beijing 100850, China; \\ ${ }^{2}$ China Institute of Atomic Energy, Beijing 102413, China
}

Received January 20, 2013; accepted March 18, 2013; published online July 12, 2013

\begin{abstract}
Clustered DNA damage is considered as a critical type of lesions induced by ionizing radiation, which can be converted into the fatal or strong mutagenic complex double strand breaks (DSBs) during damage processing in the cells. The new data show that high energy protons produce more potentially lethal DSBs than low LET radiation. In this study, plasmid DNA were used to investigate and re-evaluate the biological effects induced by the protons with the LET of $\sim 3.6 \mathrm{keV} / \mu \mathrm{m}$ at the molecular level in vitro, including single strand breaks (SSBs), DSBs, isolated and clustered base damages. The results of complex DNA damage detections indicated that protons at the given LET value induce about 1.6 fold more non-DSB clustered DNA damages than the prompt DSB. The DNA damage yields by protons were greater than that by $\gamma$-rays, specifically by 6 fold for the isolated type of DNA damage and 14 fold for the clustered damage. Furthermore, the spectrum of damages was also demonstrated to be depended on the radiation quality, with protons producing more DSBs relative to clusters than do $\gamma$-rays.
\end{abstract}

proton, plasmid DNA, linear energy transfer, double strand breaks, clustered DNA damage

Citation: Sui L, Wang Y, Wang X, et al. Clustered DNA damage induced by protons radiation in plasmid DNA. Chin Sci Bull, 2013, 58: 3217-3223, doi: $10.1007 / \mathrm{s} 11434-013-5940-\mathrm{x}$

In the space radiation field, the primary components are galactic cosmic rays (GCR) and solar particle events (SPE). GCR particles consist of $87 \%$ protons, $12 \%$ alpha particles and about $1 \%$ of heavy ions. SPE particles are mainly protons. Among these, protons are obviously the most abundant type of charged particles [1]. Model calculations have suggested that, during transit to Mars, every cell in an astronaut's body would be hit by a proton every few days $[2,3]$. On earth, worldwide over 40000 cancer patients have received proton radiotherapy [4]. The increasing use of proton radiotherapy necessitates strengthening the study of the basic biological mechanisms associated with exposure to protons. In generally, protons are classified as low linear energy transfer (LET) like the photon from $\mathrm{X}$ and $\gamma$-rays, that is to say they do not lose much energy when they pass through the matter. DNA is one of the most important targets of ionizing radiation, and the double-strand breakage

*Corresponding author (email: zhoupk@nic.bmi.ac.cn)
(DSB) is a particularly hazardous type of DNA damage to dividing cells as it involves a break to both strands nearby in the double helix [5]. The data of Hada and Sutherland [6] indicate that high energy ( $1 \mathrm{GeV} /$ nucleon, $0.22 \mathrm{keV} / \mu \mathrm{m})$ protons produce more potentially lethal double-strand breaks (DSBs) than low LET radiation, and the spectrum of damages is very similar to that of high energy iron ions and other heavy charged particles. The distinctive biological mark of heavy ions with high LET is to induce complex DNA damage, including DSBs and non-DSB clustered DNA damage. Clustered lesions are defined as two or more lesions (base damage, single strand break, abasic site) formed within a $\sim 10$-bp segment by a single radiation track. Both DSBs and non-DSB clustered DNA damages are considered difficult to be repaired and are closely associated with mutations and cell death. So for re-evaluating the effects of protons on biological systems, it is important to further investigate these two types of complex damages, induced by whether high or low energy protons. To our 
knowledge, although there are series of research reports regarding the efficiencies of DSBs and non-DSB clustered DNA damage induction by high or low LET radiation [7-18], very few experimental studies were conducted on the comparison of protons with heavy ions or low LET radiation. In a former report, the energy of protons and the buffer solution surrounding of DNA used is different [19], so the disaccord about yields of clustered DNA damage exist. In experiment of Leloup et al. [19], pHAZE plasmid DNA was irradiated with $1.03,19.3$ and $249 \mathrm{MeV}$ protons (LET $=25.5,2.7$ and $0.39 \mathrm{keV} / \mu \mathrm{m}$ respectively) in phosphate buffer containing $2 \mathrm{mmol} / \mathrm{L}$ or $200 \mathrm{mmol} / \mathrm{L}$ glycerol, the results have shown that single-strand breaks (SSBs) yield decreased with increasing LET, the yield of DSB and all clustered lesions seemed to reach a minimum around 3 $\mathrm{keV} / \mu \mathrm{m}$. There was a higher yield of SSB, DSB and total clustered lesions for DNA in $2 \mathrm{mmol} / \mathrm{L}$ glycerol compared to that in $200 \mathrm{mmol} / \mathrm{L}$ glycerol, which is similar to the data of Sutherland et al. [20]. The latter indicated that the microenvironment around DNA has a significant effect on cluster induction. The Tris-buffer (radioquenching) was reported to reduce the yields of all clustered damages induced by $\gamma$-rays irradiation to $1 \%-3 \%$ of the levels formed in phosphate solution (non-radioquenching) under the same radiation dose, and the spectrum of clusters has also changed [20]. In addition, the yields of DNA damage also depend on the type or size of DNA molecules. For example, the paper of Terato et al. showed that the ratio of total clustered versus isolated damage for lambda DNA was higher than that for pDEL19 plasmid DNA irradiated with ${ }^{60} \mathrm{Co}$ $\gamma$-rays, carbon and iron ions [10]. Therefore, it is necessary to conduct further study of biological effects induced by protons radiation. In present study, the plasmid pUC19 DNA samples were irradiated with protons and $\gamma$-rays in the presence of $200 \mathrm{mmol} / \mathrm{L}$ Tris-HCl buffer as a scavenger to provide cell mimetic conditions, and then these irradiated DNA samples were treated with the lesion-specific baseexcision repair enzymes endonuclease III (Nth) and formamidopyrimidine-DNA glycosylase (Fpg), to convert the base lesions into the form of DNA breakage. The clustered DNA damage was evaluated by analyzing the DNA molecular conformation changes in gel electrophoresis. The data from this study would be beneficial to the risk estimation on crews in case of exposure to space radiation and the victims of other nuclear radiation exposure, and also provide the essential experimental information of biological basis for the proton radiation therapy.

\section{Materials and methods}

\subsection{DNA preparation}

The purified DNA sample, pUC19 double-stranded plasmid (2686 bp) was purchased from TaKaRa Biotechnology Co. Ltd. (Dalian, China). The plasmid was primary of $(>90 \%)$ supercoiled form. The original concentration of DNA was $500 \mathrm{ng} / \mu \mathrm{L}$. For the irradiation experiment, the DNA sample was diluted and dissolved in $200 \mathrm{mmol} / \mathrm{L}$ Tris- $\mathrm{HCl}$ buffer, $\mathrm{pH} 8.0$, to a concentration of $100 \mathrm{ng} / \mu \mathrm{L}$. For each radiation group, six DNA samples were prepared. One sample was used as the unirradiated control and the others were irradiated.

\subsection{Protons and $\gamma$-rays irradiation}

In the irradiation experiment, $15 \mathrm{MeV}$ of protons produced by an HI-13 tandem accelerator (China Institute of Atomic Energy, CIAE) were used. $\gamma$-rays irradiation was performed with a ${ }^{60} \mathrm{Co} \gamma$-rays source at CIAE. The pUC19 plasmid DNA was irradiated in polypropylene microtubes with protons or $\gamma$-rays at room temperature. The values of energy and corresponding LET (in aqueous solution) were 13.6 $\mathrm{MeV}$ and $3.6 \mathrm{keV} / \mu \mathrm{m}$ at the entrance surface of the DNA sample for protons radiation. A plastic scintillator detector was set to monitor the irradiated doses. The dose and dose rate of $\gamma$-irradiation was calibrated with Fricke dosimetry. The doses were 50,100, 200, 300 and 500 Gy for protons and $\gamma$-rays (LET $0.2 \mathrm{keV} / \mu \mathrm{m}$ ) irradiation. The dose rates were $8 \mathrm{~Gy} / \mathrm{min}$ for protons and $10 \mathrm{~Gy} / \mathrm{min}$ for $\gamma$-rays. Before and after irradiation, the samples were preserved in temperature of $-20^{\circ} \mathrm{C}$ prior to use.

\subsection{Enzyme treatment of DNA}

Unirradiated/control and irradiated DNA samples were treated with sufficient quantities of homogenous preparations of a lesion-specific enzyme, E. coli Fpg enzyme or Nth enzyme (New England Biolabs Ltd., Beijing, China), recognizing and cleaving primarily oxidized purine and pyrimidine lesions, respectively [11]. For Fpg enzyme treatment, each sample was brought to final concentrations of $10 \mathrm{mmol} / \mathrm{L}$ Bis Tris Propane- $\mathrm{HCl}, 10 \mathrm{mmol} / \mathrm{L} \mathrm{MgCl}_{2}$, $1 \mathrm{mmol} / \mathrm{L}$ dithiothreitol (DTT), $\mathrm{pH} 7.0$ and $100 \mu \mathrm{g} / \mathrm{mL}$ bovine serum albumin (BSA; New England Biolabs). For Nth enzyme treatment, each sample was brought to final concentrations of $20 \mathrm{mmol} / \mathrm{L}$ Tris-HCl, $1 \mathrm{mmol} / \mathrm{L}$ EDTA, $1 \mathrm{mmol} / \mathrm{L}$ DTT, pH 8.0 and $100 \mu \mathrm{g} / \mathrm{mL}$ BSA. Then all of samples were incubated with the lesion-specific enzyme at $37^{\circ} \mathrm{C}$ for $1 \mathrm{~h}$ to cleave at all substrate sites with a minimum of nonspecific cleavage and the reaction was stop by the addition of $100 \mathrm{mmol} / \mathrm{L}$ EDTA. After the reaction, the samples were preserved in temperature of $-20^{\circ} \mathrm{C}$ immediately. The quantity of enzyme to be used was determined by titrating pUC19 DNA irradiated with 50 Gy of $\gamma$-rays with increasing quantities of Fpg or Nth enzyme and determining the amount that provided maximal cleavage of specific sites with minimal nonspecific cleavage of an equal quantity of unirradiated DNA. For 500 ng DNA, 2 units (U) of Fpg or $6 \mathrm{U}$ of Nth protein was used. 


\subsection{Isolated and clustered DNA damage measurement}

All of the DNA samples, including unirradiated/control and irradiated DNA with or without enzyme treatment, were added to a gel $6 \times$ loading buffer solution $(0.05 \%$ bromophend blue, $0.035 \%$ xylene cyanol $\mathrm{FF}, 36 \%$ glycerol, 30 $\mathrm{mmol} / \mathrm{L}$ EDTA) and were separated on a $1 \%$ agarose gel pre-stained with ethidium bromide $(\mathrm{EtBr})$ in $0.5 \times \mathrm{TBE}(44.5$ $\mathrm{mmol} / \mathrm{L}$ Tris, $44.5 \mathrm{mmol} / \mathrm{L}$ boric acid and $1 \mathrm{mmol} / \mathrm{L}$ EDTA) buffer at $4 \mathrm{~V} / \mathrm{cm}$ for $2 \mathrm{~h}$. Then the gel was imaged on an AlphaImager system (Alpha Innotech Corporation, USA) and the fraction of three forms of DNA, supercoiled (SC, intact DNA), open circular (OC, DNA with single-strand break, SSB) and Linear (L, DNA with double-strand break, DSB), was obtained by quantifying the density of corresponding bands with AlphaEaseFC software.

For each of unirradiated and irradiated DNA sample, the yields, SSBs of isolated damage $\left(\mathrm{SSB}_{i}\right)$, including prompt SSBs $\left(\mathrm{SSB}_{\mathrm{P}}\right)$ and $\mathrm{SSB}$ induced by Fpg $\left(\mathrm{SSB}_{\mathrm{F}}\right)$ or Nth $\left(\mathrm{SSB}_{\mathrm{N}}\right)$ were calculated from the equation $(1)[9,10]$,

$$
\mathrm{SSB}_{\mathrm{i}}=10^{6} /\left(D_{37} \times 2686\right)
$$

where $i=\mathrm{P}, \mathrm{F}$, or $\mathrm{N}$ is defined above, $D_{37}$ is the dose required to give an average of $1 \mathrm{SSB}$ per pUC19 molecule (2686 bp).

The yields of oxidized purine and pyrimidine lesions were determined with the following equations [10],

$$
\begin{gathered}
\text { Oxidized purines }=\mathrm{SSB}_{\mathrm{F}}-\mathrm{SSB}_{\mathrm{P}} \\
\text { Oxidized pyrimidines }=\mathrm{SSB}_{\mathrm{N}}-\mathrm{SSB}_{\mathrm{P}}
\end{gathered}
$$

The yields, DSBs of clustered damage, including prompt DSBs $\left(\mathrm{DSB}_{\mathrm{P}}\right)$ and non-DSBs clustered induced by Fpg $\left(\mathrm{DSB}_{\mathrm{F}}\right)$ or Nth $\left(\mathrm{DSB}_{\mathrm{N}}\right)$ were determined from the slope of dose-response curves for the formation of L DNA $[9,10]$. The yields of oxidized purine and pyrimidine clusters were calculated from the equation (4) and (5) [10], respectively.

$$
\begin{gathered}
\text { Oxidized purine clusters }=\mathrm{DSB}_{\mathrm{F}}-\mathrm{DSB}_{\mathrm{P}} \\
\text { Oxidized pyrimidine clusters }=\mathrm{DSB}_{\mathrm{N}}-\mathrm{DSB}_{\mathrm{P}}
\end{gathered}
$$

\section{Results and discussion}

In order to effectively convert all the isolated or clustered base damages to SSBs or DSBs, the amount of enzyme required for the complete cleavage of all substrate sites presented in the DNA samples was firstly determined. The results indicated that, after the enzyme treatment, only the fraction of OC form (SSB) increased in the DNA samples irradiated with $\gamma$-rays, meaning that mainly some isolated base damages exist. For the unirradiated DNA sample, there is only a few augmentations on the amount of OC form DNA molecules, indicating that the control DNA samples contain very few endogenous base damages. Figure 1 presents typical titration curve for induction of Nth enzyme

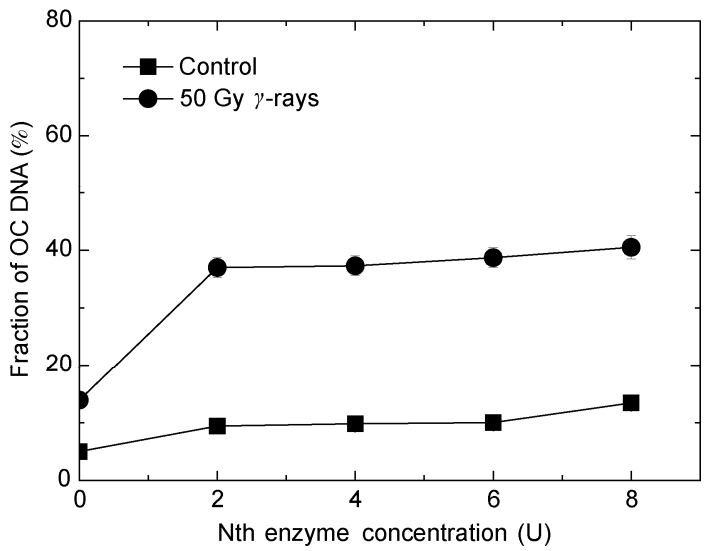

Figure 1 Titration curve for Nth enzyme amount against the production of OC form molecules in the plasmid DNA unirradiated or irradiated with $\gamma$-rays.

concentration against the production of OC form DNA by effectively cleaving the base damages in control or 50 Gy $\gamma$-rays irradiated plasmid DNA samples. Therefore, 2-6 U of the Nth enzyme is sufficient for the complete cleavages at all available base damages in samples. The quantity of Fpg enzyme was determined in a similar way (data not shown).

The confirmation of protons-induced clustered DNA damage demonstrated by the migration patterns in the electrophoresis gel is shown in Figure 2(a). Lane 1 is length markers of standard DNA. Lanes 5-9 show DNA samples without enzyme treatment and the exposure doses were 50, 100, 200, 300 and $500 \mathrm{~Gy}$, respectively. Lanes 10-14 and 15-19 are DNA samples treated with Fpg or Nth enzyme. Unirradiated DNA incubated under the same conditions with or without enzyme shows in lanes $2-4$, indicating that the processes of enzyme preparations and cleavage reaction have little nonspecific cleavage, and very few endogenous clusters were produced for the DNA preparation. For each system, the forms of irradiated DNA samples changed from $\mathrm{SC}$ to $\mathrm{OC}$ and $\mathrm{L}$ as the dose increased. When the DNA were irradiated with the dose up to $500 \mathrm{~Gy}$, the SC form of molecules almost completely disappeared, and all converted into the forms of circular, linear forms as well as the smear. The smear was a compounding of short DNA fragments in a wide range of molecular weights and reflected multiple sites of the clustered DNA damages existed in a molecule. This type of severity clustered DNA damages was converted to multiple double-strand breaks after the enzymatic cleavage, and consequently resulted in multi-fragmentation of DNA molecule. But compared with the DNA without enzyme treatment, the DNA samples treated with Fpg or Nth enzyme exhibit much higher level of the fraction of OC and L forms at the same dose, and the smear DNA emerged and increased dose-dependently starting from dose of $200 \mathrm{~Gy}$. This phenomenon is similar to the report of Hada et al. [6], in which the T7 DNA were irradiated with ion beams (iron, carbon, titanium, silicon, protons) or $100 \mathrm{kVp} \mathrm{X}$ rays [6]. 

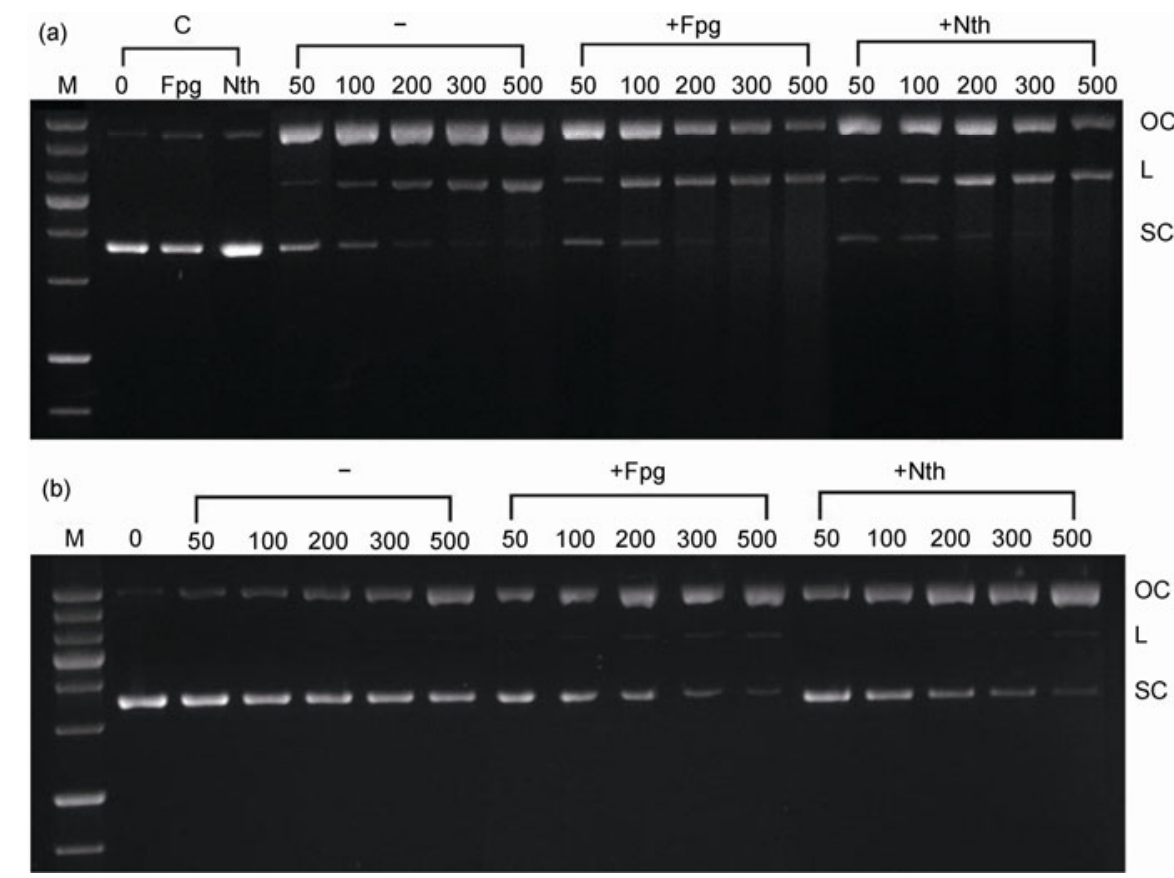

Figure 2 Gel electrophoresis image of DNA treated with and without enzyme after protons or $\gamma$-rays irradiation. DNA in $200 \mathrm{mmol} / \mathrm{L}$ Tris- $\mathrm{HCl}$ buffer was unirradiated or was irradiated with proton (a) or ${ }^{60} \mathrm{Co} \gamma$-rays (b). $\mathrm{M}$ is molecular length markers of standard DNA, C is unirradiated DNA samples treated with and without enzyme, $0,50,100, \cdots, 500 \mathrm{~Gy}$ is exposed doses. "-" represents DNA samples in the absence of enzyme, "+Fpg" and "+Nth" represents DNA samples treated with Fpg or Nth enzyme.

Furthermore, after enzyme treatment, the total amount of DNA obviously decreased with the dose increasing, which reveals that more and more numbers of isolated and clustered damages, such as SSB, base damage and glycation damage produced in plasmid DNA after proton irradiation. These clustered-damage DNA molecules were consequently changed from SC and OC to OC or L form after treated with the enzymes.

Figure 2(b) shows a representative gel electrophoresis image of DNA damage induced by $\gamma$-rays irradiation and the conformation of DNA changed in a similar way with proton. But the extent of damage is obviously lower than that of proton. There still retained a certain amount of the intact SC form DNA even at the dose of $500 \mathrm{~Gy}$, and the amount of L form is also very low. For example, the $\mathrm{L}$ form DNA is scarcely detected and quantified in the 500 Gy $\gamma$-rays irradiated DNA sample without further enzyme treatment, as well as the 200 Gy $\gamma$-rays irradiated DNA sample even after treated with Nth enzyme. The result is consistent with previous paper of Gulston et al. [9], in which the detection was conducted on ${ }^{60} \mathrm{Co} \gamma$-rays irradiation of pUC18 plasmid DNA in aqueous aerated solution containing $200 \mathrm{mmol} / \mathrm{L}$ Tris as a scavenger at the same dose. Furthermore, comparison of DNA treated with and without enzyme, the enzyme-increased amount of OC form DNA is much more than that of $\mathrm{L}$ form DNA, indicating that $\gamma$-rays radiation can mainly induce the isolated prompt damage, such as SSB, base damage and so on, but not or quite few clustered complex damages.

With the two types of radiation sources used, the fraction of SC and L DNA, as quantified from the gel images as the representatives of Figure 2(a) and (b), is plotted as a function of radiation doses in Figure 3. The fraction of SC DNA decreases exponentially as dose increased. The post- treatment of irradiated DNA with Fpg or Nth lead to a further decrease of SC DNA (Figure 3(a), (c)), indicating the presence of isolated oxidized base damages lesions in irradiated DNA. The results also show that the changing trend is all straight line, which in accordance with the target theory, $y=a \times \exp \left(-D / D_{37}\right)$, here $D$ represents the value of radiation dose, $D_{37}$ is same meaning as equation (1). Fitted by the formula, the $D_{37}$ of protons and $\gamma$-rays was obtained, and the yields of isolated damage, including prompt SSBs, oxidized purine and pyrimidine were determined from the $D_{37}$ doses. The fraction of L DNA displays a good linear relationship with the irradiation dose, and post-treatment with Fpg or Nth resulted in further increases of L DNA (Figure 3(b), (d)), indicating the presence of non-DSB, oxidized purine and pyrimidine clusters in irradiated DNA. The yields of clustered damages, such as prompt DSBs, oxidized purine and pyrimidine clusters were determined from the slopes of dose response curves. Furthermore, protons produce much more DSB and non-DSB clusters than that produced by $\gamma$-rays irradiation.

From the above data, the fraction of isolated (prompt SSBs, oxidized purine and pyrimidine, Figure 4(a)) and clustered (prompt DSBs, oxidized purine and pyrimidine clusters, Figure 4(b)) damage induced by protons, as a function of radiation doses, was obtained and is shown in Figure 4. For the isolated damage, shift of fraction of SSB, oxidized 

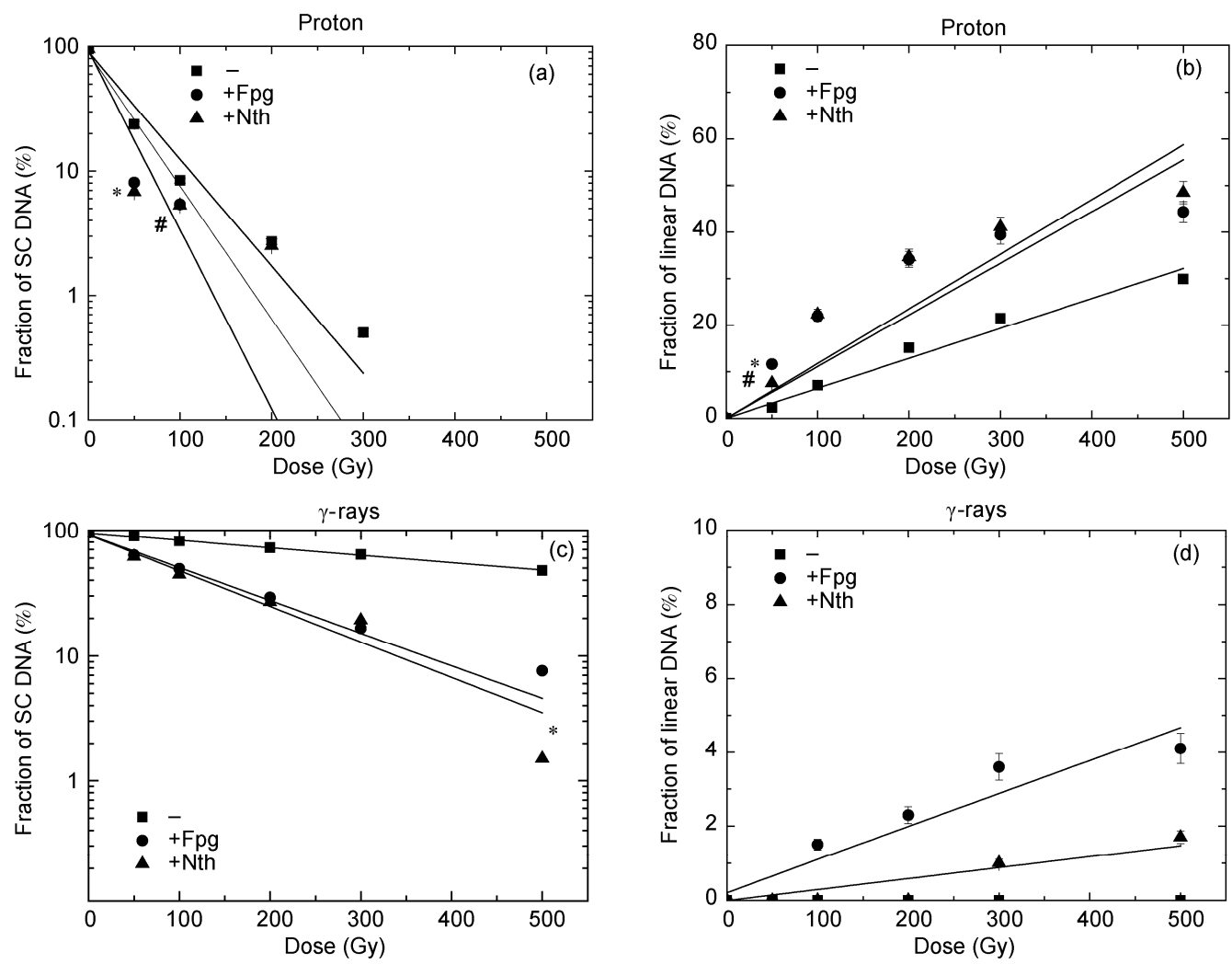

Figure 3 Fraction of SC and L DNA as a function of radiation doses. Statistical significance for the difference between the treatment with and without enzyme is indicated by * for $P<0.01$ and \# for $P<0.05$.
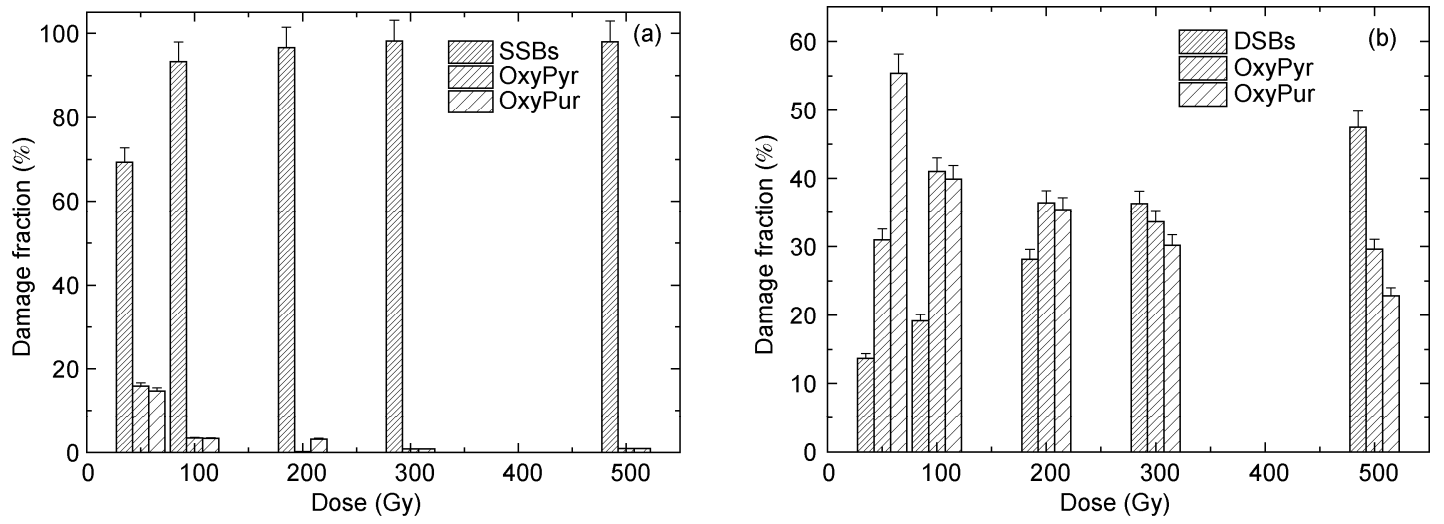

Figure 4 Fraction of isolated and clustered damage as a function of the proton dose.

purine and pyrimidine is independence of dose, only shows increase with increasing doses below 200 Gy for SSB. For the clustered damages, the DSB and oxidized purine clusters depend significantly on dose, and display increase for DSB and decrease for oxidized purine clusters as the dose increased, respectively. Based on the equations (1)-(5), the yields (sites $/ 10^{6} \mathrm{bp} / \mathrm{Gy}$ ) of each of isolated and clustered damage induced by protons and $\gamma$-rays, were determined and summarized in Table 1. The results indicate that protons induce more prompt DSB than non-DSB clusters (Fpg and Nth cluster), which is very similar to high LET radiations, and the latter has already been proven in most cases [11].
For $\gamma$-rays, the non-DSB clusters tend to be higher compared to prompt DSB which have already verified at low LET radiations $[6,10]$. The yields induced by protons, whatever prompt SSB or DSB and isolated or clustered base damages, are significantly greater than that of $\gamma$-rays, and the total yields about by 6 fold for isolated and 14 fold for clustered damages, respectively. The ratio of yields of the total clustered versus isolated damage is $0.61 \%$ for protons and $0.29 \%$ for $\gamma$-rays, suggesting that protons induce much more clustered damages. This may be explained by a qualitatively different damage mechanism active in the case of $\gamma$-rays and protons. For low LET $\gamma$-rays radiation, DNA 
Table 1 Yields of isolated and clustered damages induced by proton and $\gamma$-rays radiation

\begin{tabular}{lcc}
\hline \multirow{2}{*}{ Damage } & \multicolumn{2}{c}{ Yields (sites $\left./ 10^{6} \mathrm{bp} / \mathrm{Gy}\right)$} \\
\cline { 2 - 3 } & \multicolumn{1}{c}{$P$} & $\gamma$-rays \\
\hline Isolated damage & $9.95 \pm 0.79$ & $0.51 \pm 0.03$ \\
SSBs & $8.95 \pm 0.72$ & $1.92 \pm 0.13$ \\
oxidized pyrimidines & $7.61 \pm 0.68$ & $1.72 \pm 0.12$ \\
oxidized purines & $26.51 \pm 2.19$ & $4.15 \pm 0.28$ \\
total & & \\
Clustered damage & $0.064 \pm 0.009$ & 0 \\
DSBs & $0.053 \pm 0.008$ & $0.003 \pm 0.0005$ \\
oxidized pyrimidine clusters & $0.047 \pm 0.008$ & $0.009 \pm 0.0015$ \\
oxidized purine clusters & $0.164 \pm 0.025$ & $0.012 \pm 0.0011$ \\
total & & \\
\hline
\end{tabular}

damage is mainly due to attack by indirect effect, i.e. water radiolysis generated toxic products such as ${ }^{\circ} \mathrm{OH}$ free radical that then reacted with the DNA. Under cell mimetic conditions with high scavenger concentration, the efficient scavenging of ${ }^{\circ} \mathrm{OH}$ radicals almost completely suppressed the formation of $\mathrm{L}$ to an undetectable level and induced lowest yields of DSB. In addition, typical ${ }^{\circ} \mathrm{OH}$ diffusion length is about few nanometers in the absence of scavengers, and under this circumstance each plasmid may be only interacts with radical in its direct neighborhood. However, for protons of higher LET, the interaction with DNA is a corporate result of direct effect and indirect effect of free radicals. In the presence of the scavenger Tris-HCl, DSB and non-DSB clusters induced by direct action or locally multiply damaged sites (LMDS), can not be scavenged and are in higher yields. Furthermore, another reason is that DSB and other clustered lesions are mainly formed by very close local regions of higher ionization density in radiation fields, and for proton with higher LET radiation, these regions are closely spaced and more frequent than low LET. Therefore, the increasing of size of ionization clusters, and also of ${ }^{\circ} \mathrm{OH}$ radical clusters are helpful for the production of DSB and clustered lesions upon proton irradiation. This also can be interpreted as that the protons have the radial denser track structure compared to $\gamma$-rays, leading to denser ionizations and radical formation, and deposit more energy within a radius of a few nanometers around the ion track, favoring clustered damage. Compared with previous reports [11,13], the DSB yield by irradiation of $\gamma$-rays in presence of high scavenger is much lower and seems to be close to zero in the present study. This result could be considered to be associated with these factors, such as the type of DNA (DNA sequence), the buffer solution surrounding of DNA, radiation dose, and different LET of $\gamma$-rays used, As the frequency of DNA DSB production is so low and almost can not be detected, a slight underestimation could also be possible than the level of real ones, depending on the dose. The DSB and non-DSB cluster yields for protons radiation, in present study, show the same order as those reported by Leloup et al. [19]. In Leloup's study, the pHAZE DNA irradiation was conducted in the radioquenching solution (200 $\mathrm{mmol} / \mathrm{L}$ glycerol). While our result seems at variance with that reported by Hada et al. [6,11], in which the T7 DNA was used and irradiated in non-radioquenching solution (20 $\mathrm{mmol} / \mathrm{L}$ phosphate buffer) $[6,11]$, and the yields are significantly greater, about by more than 100 fold. Taken together, it further implies that DNA damage production not only depends on the radiation quality, but also on conditions in which DNA was irradiated.

The spectrum of isolated and clustered damages, induced by protons and $\gamma$-rays radiation, is shown in Figure 5 . These data indicate that in irradiated DNA, compared with the
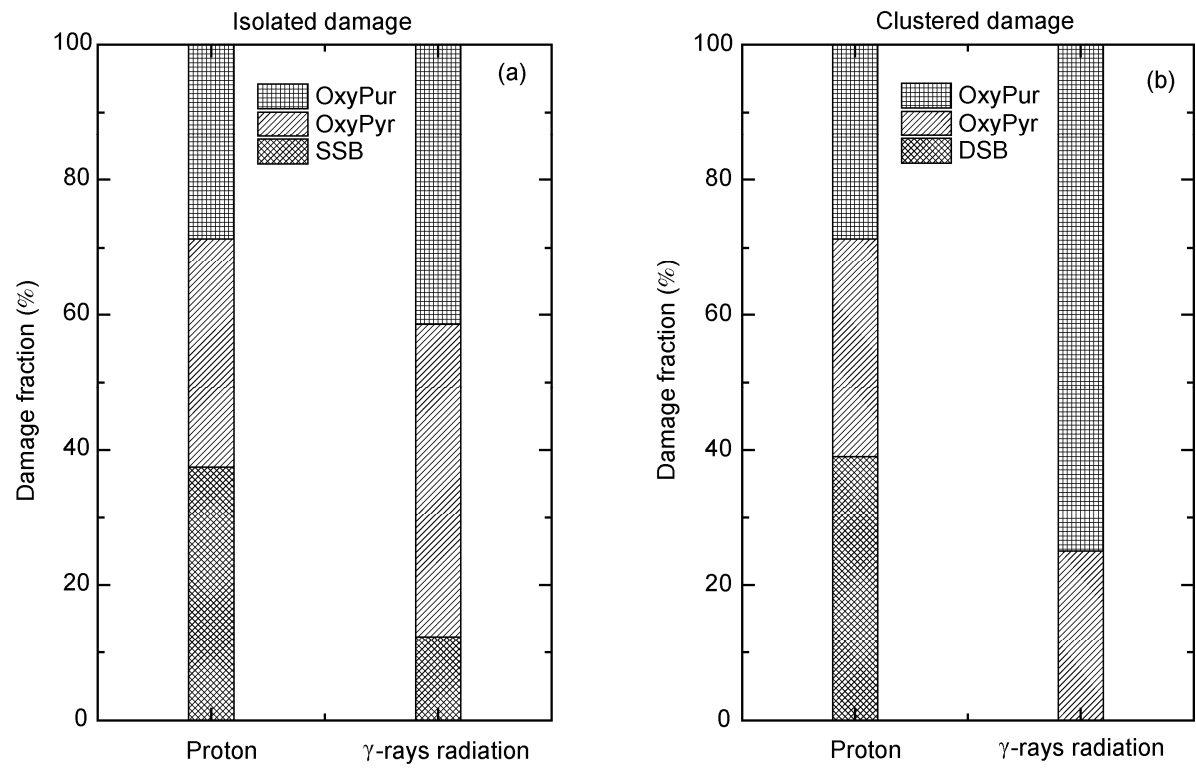

Figure 5 Spectra of isolated and clustered damage induced by proton and $\gamma$-rays radiation. 
$\gamma$-rays, the protons radiation induces a different spectrum of damages, i.e. level of DSB relative to non-DSB clusters is in a similar way with high energy iron ions and other heavy charged particles mentioned in the report of Hada et al. [6]. Therefore, the frequencies of the various complex damages obviously depend on the type of incident radiation, which could be formed by different mechanisms, including direct action of the radiation, secondary particle produced from interaction between proton and material, low-energy electrons at the end of tracks, and radicals from ionization of water or of DNA constituents. The result of spectrum also shows that, isolated or clustered damage, whether for protons or $\gamma$-rays, the total amount of oxidized base damages are greater than that of prompt SSB and DSB, revealing the importance of base damages in radiobiological effect. Similar results have been reported by Terato for $\gamma$-rays, carbon ion and iron ions irradiation of pDEL19 plasmid DNA in aqueous solution [10].

\section{Conclusions}

Comparing with $\gamma$-rays radiation, $3.6 \mathrm{keV} / \mu \mathrm{m}$ protons have a strong capability to induce the isolated and clustered damages and the damage yields are greater. The yields and spectra of complex damage in plasmid pUC19 DNA irradiated with protons are much more similar to these produced by heavy ions with high LET and high energy protons. Our data clearly point out the necessity to carry on further researches to understand the mechanism of effects of lowenergy protons on biological systems, which may be very helpful for routine cancer-tumor therapy of protons.

This work was supported by the National Science Foundation for Distinguished Young Scholars of China (30825011) and the National Natural Science Foundation of China (10805078).

1 Yang C X, Mei M T. Space Radiobiology (in Chinese). Guangzhou: Zhongshan University Press, 1995. 7-12

2 Hada M, Meador J A, Cucinotta F A, et al. Chromosome aberrations induced by dual exposure of protons and iron ions. Radiat Environ Biophys, 2007, 46: 125-129
3 Schimmerling W, Cucinotta F A. Dose and dose rate effectiveness of space radiation. Radiat Prot Dosim, 2006, 122: 349-353

4 Engelsman M, DeLaney T F, Hong T S. Proton radiotherapy: The biological effect of treating alternating subsets of fields for different treatment fractions. Int J Radiat Oncol Biol Phys, 2011, 79: 616-622

5 Zhou P K. DNA damage, signaling and repair: Protecting genomic integrity and reducing the risk of human disease. Chin Sci Bull, 2011, 56: $3119-3121$

6 Hada M, Sutherland B M. Spectrum of complex DNA damages depends on the incident radiation. Radiat Res, 2006, 165: 223-230

7 Shikazono N, Noguchi M, Fujii K, et al. The yield, processing, and biological consequences of clustered DNA damage induced by ionizing radiation. J Radiat Res, 2009, 50: 27-36

8 Purkayastha S, Milligan J R, Bernhard W A, et al. On the chemical yield of base lesions, strand breaks, and clustered damage generated in plasmid DNA by the direct effect of X rays. Radiat Res, 2007, 168: 357-366

9 Gulston M, Fulford J, Jenner T, et al. Clustered DNA damage induced by $\gamma$ radiation in human fibroblasts (HF19), hamster (V79-4) cells and plasmid DNA is revealed as Fpg and Nth sensitive sites. Nucleic Acids Res, 2002, 30: 3464-3472

10 Terato H, Tanaka R, Nakaarui Y, et al. Quantitative analysis of isolated and clustered DNA damage induced by gamma-rays, carbon ion beams and iron ions beams. J Radiat Res, 2008, 49: 133-146

11 Hada M, Georgakilas A G. Formation of cluster DNA damage after high-LET radiation: A review. J Radiat Res, 2008, 49: 203-210

12 Georgakilas A G. Processing of DNA damage clusters in human cells: Current status of knowledg. Mol Biosyst, 2008, 4: 30-35

13 Sutherland B M, Bennett P V, Sidorkina O, et al. Clustered DNA damages induced in isolated DNA and in human cells by low doses of ionizing radiation. Proc Natl Acad Sci USA, 2000, 97: 103-108

14 Prise K M, Pullar C H L, Michael B D. A study of endonuclease III-sensitive sites in irradiated DNA: Detection of $\alpha$-particle-induced oxidative damage. Carcinogenesis, 1999, 20: 905-909

15 Milligan J R, Aguilera J A, Paglinawan R A, et al. DNA strand break yields after post-high LET irradiation incubation with endonuclease-III and evidence for hydroxy radical clustering. Int J Radiat Biol, 2001, 77: 155-164

16 Terato H, Ide H. Clustered DNA damage induced by heavy ion particles. Biol Sci Space, 2004, 18: 206-215

17 Tsao D, Kalogerinis P, Tabrizi I, et al. Induction and processing of oxidative clustered DNA lesions in ${ }^{56} \mathrm{Fe}$-ion-irradiated human monocytes. Radiat Res, 2007, 168: 87-97

18 Kong F Q, Zhao K, Zhan Y, et al. Analysis of length distribution of short DNA fragments induced by ${ }^{7} \mathrm{Li}$ ions using the random-breakage model. Chin Sci Bull, 2005, 50: 841-844

19 Leloup C, Garty G, Assaf G, et al. Evaluation of lesion clustering in irradiated plasmid DNA. Int J Radiat Biol, 2005, 81: 41-54

20 Sutherland B M, Bennett P V, Weinert E, et al. Frequencies and relative levels of clustered damages in DNA exposed to gamma rays in radioquenching vs. nonradioquenching conditions. Environ Mol Mutagen, 2001, 38: 159-165

Open Access This article is distributed under the terms of the Creative Commons Attribution License which permits any use, distribution, and reproduction in any medium, provided the original author(s) and source are credited. 